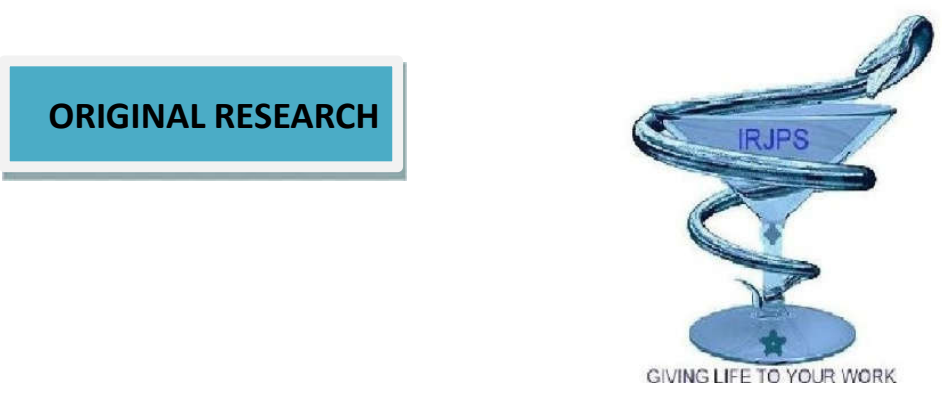

\title{
MICROENCAPSULATION OF ENALAPRIL USING DIFFERENT POLYMERS BY IONOTROPIC GELATION TECHINIQUE
}

\author{
Tahseen Sameena*, Hafsa Siddiqua, Dr. Khaja Pasha, Habeeba Sultana, Kouser Unnisa
}

Department of Pharmaceutics, Azad College of Pharmacy’ Moinabad-Chilkur Road, Hyderabad-500075

\section{Submitted on: 12.03.16; Revised on: 20.03.17; Accepted on: 24.03.17}

\begin{abstract}
:
Microsphere of Enalapril malate were formulated by ionotropic gelation technique using like sodium alginate, HPMC, carbopol 940, Guar gum, Xanthum gum in different ratios. Prepared micropeletes were evaluated for flow behavior, drug entrapment efficiency, in-vitro dissolution and stability studies, including scanning electron microscopy and optical microscopy. Of the ten formulations prepared and evaluated formulations F3 containing HPMC 100 and carbopol found to show satisfactory results. The release of the drug from the micropeletes was found to be following Non-Fickian diffusion, Drug diffusion coefficient and correlation coefficient were also assessed by using various mathematical models. From the study it was concluded that prolonged release Enalapril malate micropeletes can be achieved with success using ionotropic gelation technique.
\end{abstract}

KEYWORDS:- Captopril , ACE inhibitor, anti-hypertensive, HPMC

Corresponding Author: Tahseen Sameena, E-mail: tahseensameena1992@gmail.com
Indian Research Journal of Pharmacy and Science; 12(2017) 907-914 Journal Home Page: https://www.irjps.in 


\section{INTRODUCTION:}

Enalapril is a ACE inhibitor used in the treatment of hypertension, high blood pressure, diabetic kidney disease, and heart failure ${ }^{[1]}$ For heart failure it is generally used with a diuretic such as furosemide. It is given by mouth or injection into a vein. Onset of effects are typically within an hour when taken by mouth and last for up to day. ${ }^{[2]}$ It is usually administered as conventional tablets containing 10$40 \mathrm{mg}$, per day. In the proposed method of ion tropic gelation technique, strong spherical bed with narrow particle size distribution and low friability could be prepared with high yield and drug content approaching 98 percent.

\section{METHOD:}

PREPARATION OF MICROPELLETS: Batches of microspheres were prepared by ionotropic gelation method which involved reaction between sodium alginate and polycationic ions like calcium to produce a hydrogel network of calcium alginate. Sodium alginate and the mucoadhesive polymer were dispersed in purified water $(50 \mathrm{ml})$ to form a homogeneous polymer mixture. The API, Enalapril were added to the polymer premix and mixed thoroughly with a stirrer to form a viscous dispersion. The resulting dispersion was then added through a $22 \mathrm{G}$ needle into calcium chloride $(2 \% \mathrm{w} / \mathrm{v})$ aqueous solution. The addition was done with continuous stirring at 200rpm. The added droplets were retained in the calcium chloride solution for 30 minutes to complete the curing reaction and to produce rigid spherical microspheres. The microspheres were collected by decantation, and the product thus separated was washed repeatedly with purified water to remove excess calcium impurity deposited on the surface of microspheres and then air-dried

Table No1: Prepared Formulation of Microspheres and their physical properties

\begin{tabular}{|c|c|c|c|c|c|c|c|c|}
\hline $\begin{array}{c}\text { Formul } \\
\text { ation } \\
\text { code }\end{array}$ & $\begin{array}{c}\text { Sodium } \\
\text { alginate } \\
\mathbf{\%} / \mathbf{v}\end{array}$ & $\begin{array}{c}\text { Calcium } \\
\text { chloride } \\
\mathbf{\%} / \mathbf{v}\end{array}$ & $\begin{array}{c}\text { Guargu } \\
\mathbf{m} \\
\mathbf{\%} / \mathbf{v}\end{array}$ & $\begin{array}{c}\text { Xanthu } \\
\mathbf{m} \text { gum } \\
\mathbf{\%} / \mathbf{v}\end{array}$ & $\begin{array}{c}\text { HPM } \\
\mathbf{C} \\
\text { K100 } \\
\mathbf{\%} / \mathbf{v}\end{array}$ & $\begin{array}{c}\text { Carbop } \\
\mathbf{o l} \\
\mathbf{\%} / \mathbf{v}\end{array}$ & $\begin{array}{c}\text { Drug } \\
\text { entrapme } \\
\text { nt } \\
\text { efficiency }\end{array}$ & $\begin{array}{c}\mathbf{\%} \\
\text { yield }\end{array}$ \\
\hline F1 & $\mathbf{1 \%}$ & $\mathbf{2 \%}$ & - & - & - & $\mathbf{1}$ & 70.1 & 93.8 \\
\hline F2 & $\mathbf{1 \%}$ & $\mathbf{2 \%}$ & - & - & $\mathbf{1}$ & $\mathbf{1}$ & 83.4 & 87.6 \\
\hline F3 & $\mathbf{1 \%}$ & $\mathbf{2 \%}$ & - & - & $\mathbf{1 . 5}$ & $\mathbf{1}$ & 91.8 & 94.8 \\
\hline F4 & $\mathbf{1 \%}$ & $\mathbf{2 \%}$ & - & - & $\mathbf{2}$ & $\mathbf{1}$ & 90.4 & 95.0 \\
\hline F5 & $\mathbf{1 \%}$ & $\mathbf{2 \%}$ & - & $\mathbf{1 \%}$ & - & $\mathbf{0 . 5}$ & 71.7 & 90.1 \\
\hline F6 & $\mathbf{1 \%}$ & $\mathbf{2 \%}$ & $\mathbf{1 \%}$ & - & - & $\mathbf{0 . 5}$ & 64.3 & 95.1 \\
\hline F7 & $\mathbf{1 \%}$ & $\mathbf{2 \%}$ & - & - & - & $\mathbf{1 . 5}$ & 73.6 & 96.9 \\
\hline F8 & $\mathbf{1 \%}$ & $\mathbf{2 \%}$ & - & - & $\mathbf{0 . 7 5}$ & $\mathbf{1 . 5}$ & 91.8 & 95.1 \\
\hline F9 & $\mathbf{1 \%}$ & $\mathbf{2 \%}$ & - & - & $\mathbf{1}$ & $\mathbf{1 . 5}$ & 90.6 & 94.2 \\
\hline F10 & $\mathbf{1 \%}$ & $\mathbf{2 \%}$ & - & - & $\mathbf{2}$ & $\mathbf{1 . 5}$ & 88.2 & 90.6 \\
\hline
\end{tabular}

\section{DRUG ENTRAPMENT EFFICIENCY :} Accurately weighed 100 micropeletes were suspended in $100 \mathrm{ml}$ of simulated intestinal fluid of $\mathrm{pH} 7.2 \pm 0.1$ and kept for $24 \mathrm{hrs}$. Next day it was stirred for $5 \mathrm{~min}$, and subjected for filtration. After suitable dilution, Enalapril malate content in the filtrate was analyzed spectrophotometrically at $212 \mathrm{~nm}$ using Shimadzu 1201 UV-Visible Spectrophotometer. 
Table No 2: Drug entrapment efficiency

\begin{tabular}{||c||c||c|c||c||}
\hline \multicolumn{1}{|c||}{ S.No. } & $\begin{array}{c}\text { Formulation } \\
\text { code }\end{array}$ & \% yield & $\begin{array}{c}\text { \%Drug entrapment } \\
\text { efficiency }\end{array}$ & \% Muco adhesion \\
\hline 1 & F1 & 93.8 & 70.1 & 68.6 \\
\hline \hline 2 & F2 & 87.6 & 83.4 & 88.1 \\
\hline \hline 4 & F3 & 94.8 & 91.8 & 90.6 \\
\hline \hline 5 & F4 & 95.0 & 90.4 & 92.4 \\
\hline \hline 6 & F5 & 90.1 & 71.7 & 74.8 \\
\hline \hline 7 & F6 & 95.1 & 64.3 & 83.5 \\
\hline \hline 9 & F7 & 96.9 & 73.6 & 90.2 \\
\hline \hline 10 & F8 & 95.1 & 91.8 & 93.6 \\
\hline \hline
\end{tabular}

FLOW PROPERTY: Angle of repose method was employed to assess the flowability. Micropellets were allowed to fall freely through a funnel fixed at $1 \mathrm{~cm}$ above the horizontal flat surface until the apex of conical pile just touched the tip of the funnel. The angle of repose was determined by the formula, $\mathrm{q}=$ $\tan -1(\mathrm{H} / \mathrm{R}) ; \mathrm{H}=$ cone height of micropellets; $\mathrm{R}=$ radius of the circular base formed by the micropeletes on the ground.
IN-VITRO RELEASE STUDIES: Dissolution studies were carried out in triplicate for all the formulations, employing USP XXIII apparatus (basket method) at $50 \mathrm{rpm}$ and $37 \pm 0.50 \mathrm{C}$ using acid buffer (pH 1.2) and phosphate buffer ( $\mathrm{pH}$ 7.2) as the dissolution medium. An aliquot of the sample was periodically withdrawn at suitable time intervals and the volume replaced with fresh dissolution medium. The samples were analyzed spectrophotometrically at $212 \mathrm{~nm}$.

Figure 1: In vitro drug release profile of Enalapril microsphere ( F1-F5)

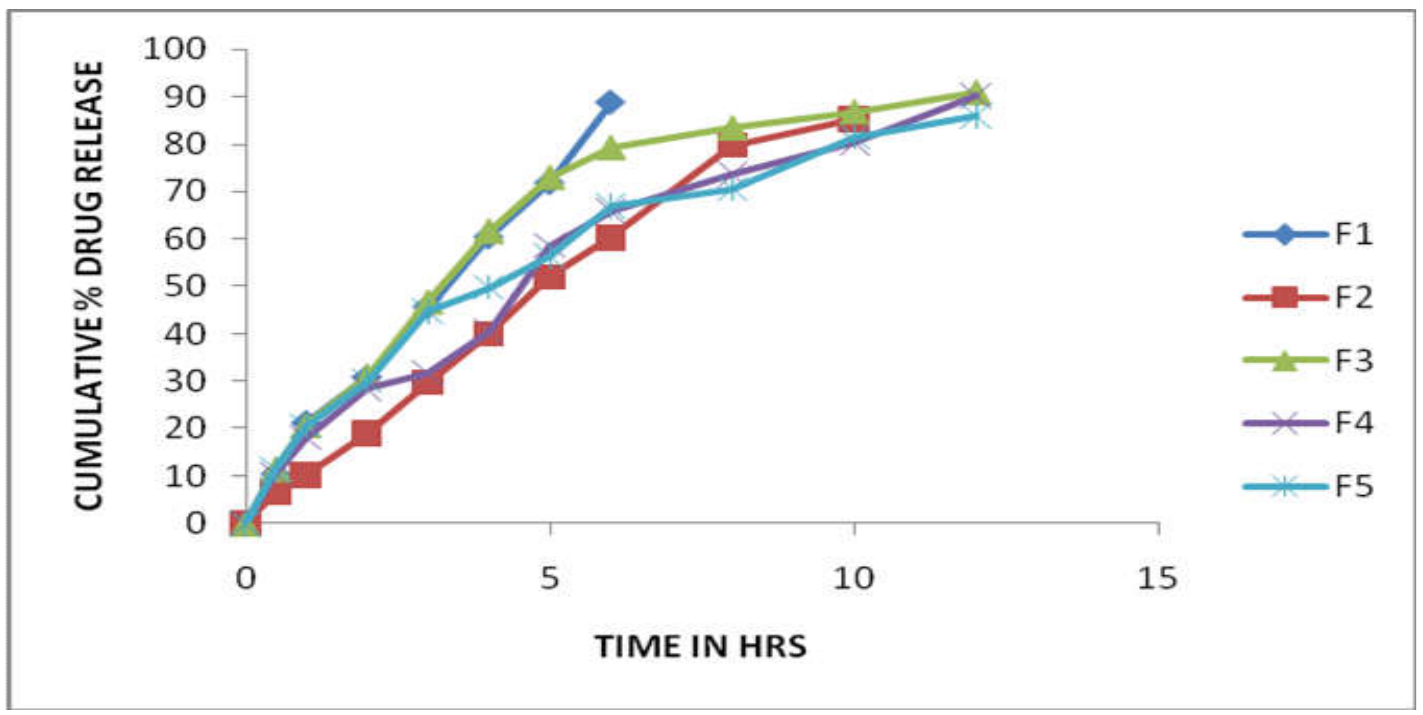


Figure 2: In vitro drug release profile of Enalapril microsphere (F6-F10)

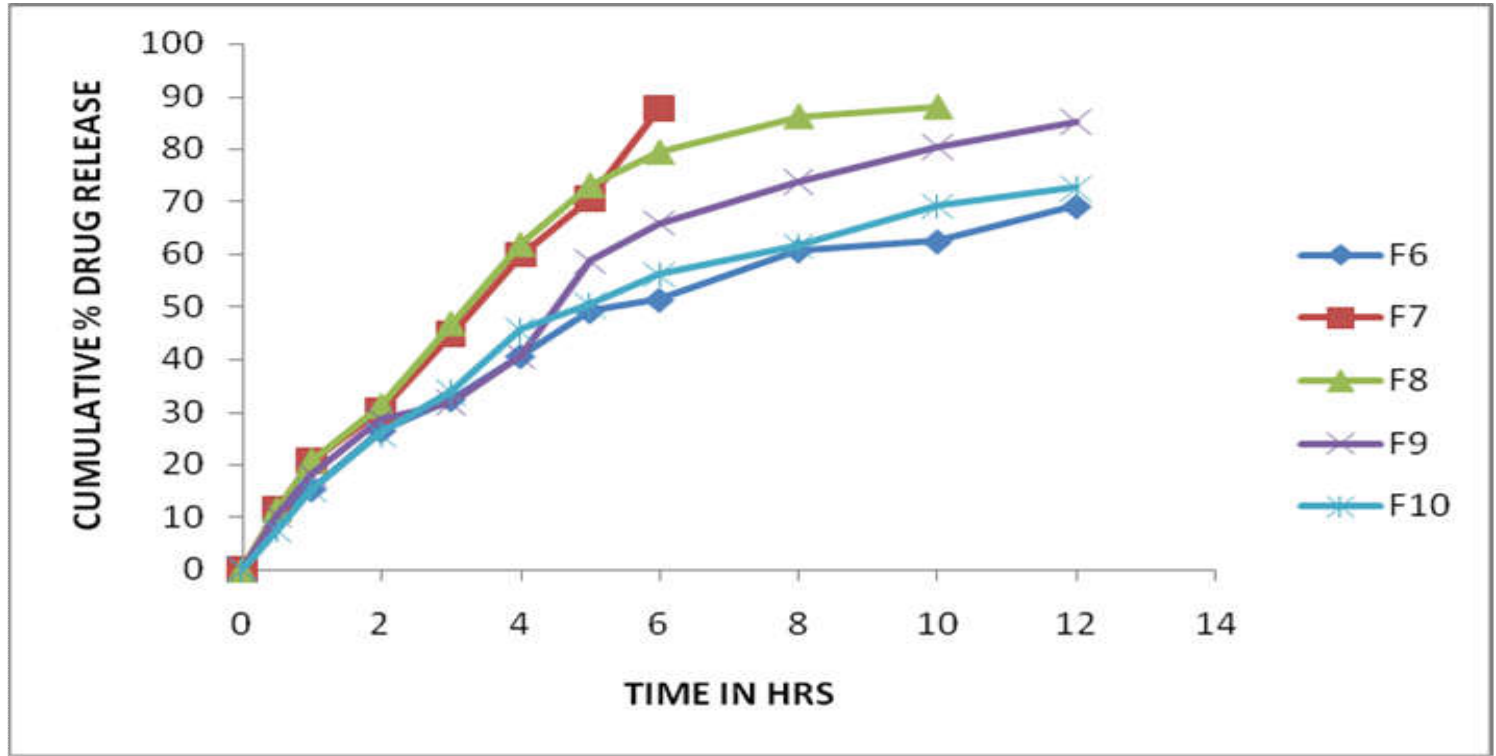

SCANNING ELECTRON MICROSCOPY (SEM)

ANALYSIS: The micropellets were observed under SEM at 2-15 $\mathrm{kV}$ by mounting sample on the aluminum stubs having double adhesive tape and subsequent evaporation of gold palladium alloy In the sputter uit. The microphotographs of suitable magnifications were obtained for surface photography.

\section{FIGURE 3: SEM of Enalapril (formulation F3)}

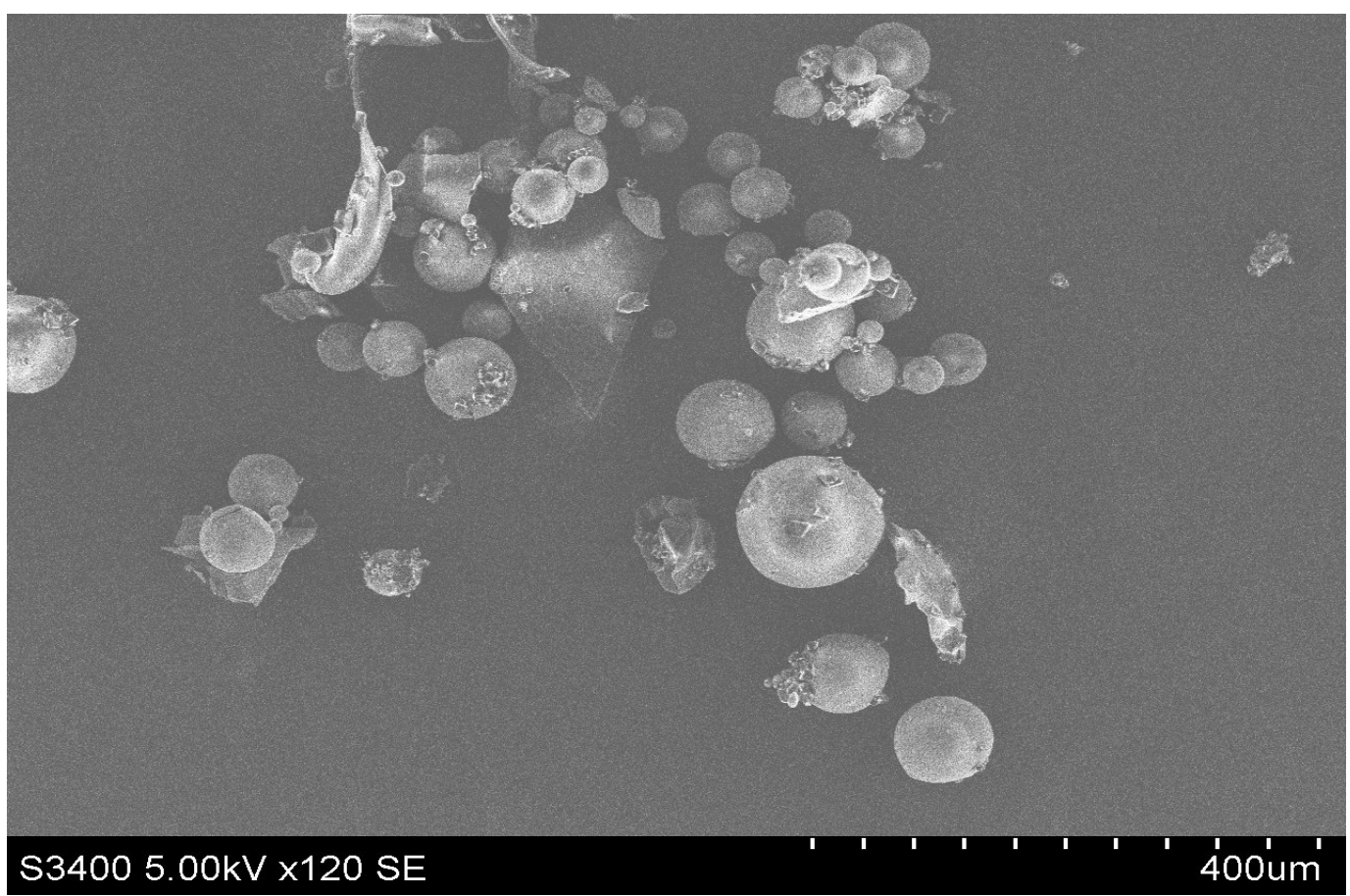


PARTICLE SIZE ANALYSIS: Samples of micropellets were analyzed for particle size by optical microscopy. The Olympus Model (SZX12) having resolution of $30 X$ was used for this purpose. The instrument was calibrated where in 1 unit of eye piece micrometer was equal to $1 / 30$ $\mathrm{mm}(33.33 \mathrm{~mm})$. All the three dimensions $(1 \mathrm{x} \mathrm{b}$ $\mathrm{x} h)$ of the micropeletes were measured.The mean particle size and size distribution of the mucoadhesive microspheres of enalapril with different drug/polymer ratio were studied and found to be in the range of $642 \mu \mathrm{m}-740 \mu \mathrm{m}$.

Table No 3: Average Particle Size analysis for formulation F1-F10

\begin{tabular}{|c||c|}
\hline Formulation code & Average particle size $(\boldsymbol{\mu m})$ \\
\hline F1 & 642 \\
\hline \hline F2 & 617 \\
\hline \hline F3 & 611 \\
\hline \hline F4 & 717 \\
\hline \hline F5 & 642 \\
\hline \hline F6 & 792 \\
\hline \hline F7 & 834 \\
\hline \hline F8 & 664 \\
\hline F9 & 702 \\
\hline F10 & 740 \\
\hline
\end{tabular}

\section{ACCELERATED STABILITY STUDIES:}

Stability studies were performed according to WHO guideline. The formulations were stored in oven at $25 \pm 2^{\circ} \mathrm{C}$ and $40 \pm 2^{\circ} \mathrm{C}$ for a period of six weeks. The samples were analyzed for drug content every week by spectrophotometer at $212 \mathrm{~nm}$.

Table No 4: Accelerated stability studies

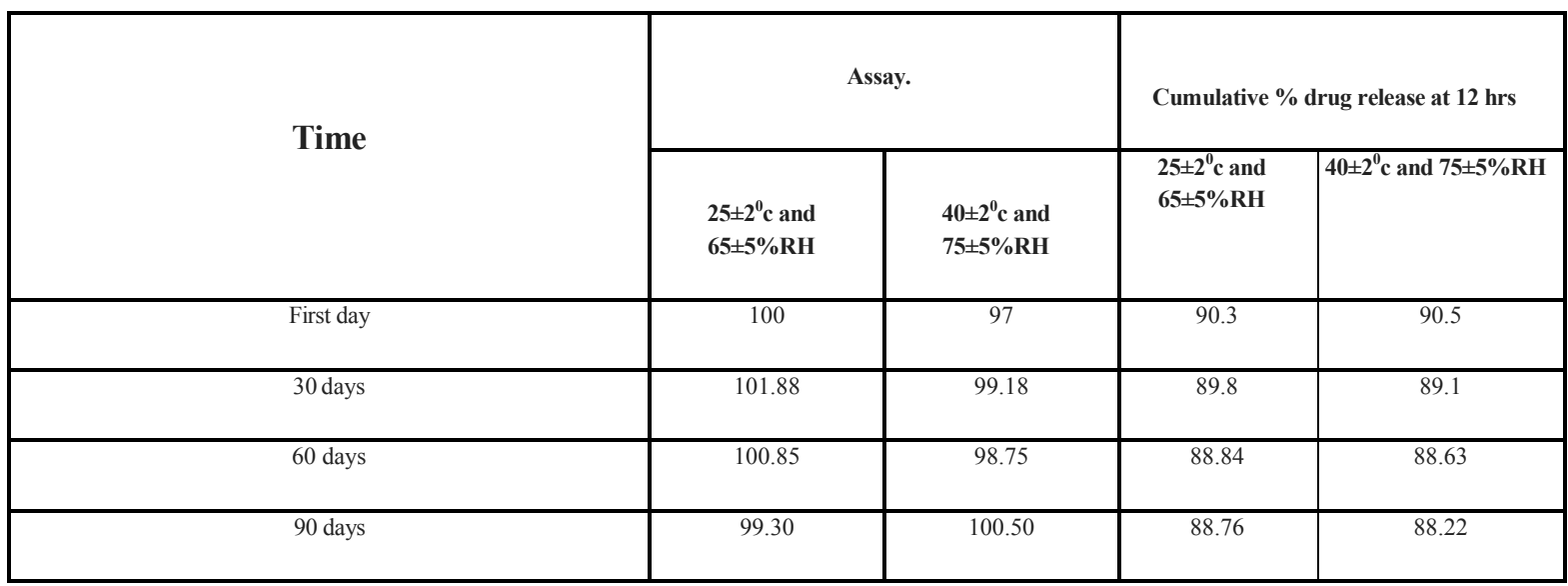

KINETICS OF DRUG RELEASE: In order to understand the mechanism and kinetics of drug release, the results of the in-vitro dissolution study of the micropellets was fitted with various kinetic equations like zero order ( $\%$ release Vs time,t), first order ( $\log \%$ remained Vs $t)$ and Korsmeyer and peppas ( $\mathrm{mt} / \mathrm{m} ¥ \mathrm{Vs} \mathrm{tn})$. ' $\mathrm{r}$ ' values were calculated for the linear curves obtained by regression analysis of the above plot 
Table No-5: Release Kinetics Studies Of The Prepared Formulations

\begin{tabular}{|c|c|c|c|c|c|}
\hline \multirow[t]{2}{*}{ Formulation } & \multirow[t]{2}{*}{ Zero order } & \multirow[t]{2}{*}{ First order } & \multirow[t]{2}{*}{ Higuchi } & \multicolumn{2}{|c|}{$\begin{array}{c}\text { Korsmeyer Peppas } \\
\text { equation }\end{array}$} \\
\hline & & & & $\left(r^{2}\right)$ & $\mathrm{n}$ \\
\hline F1 & 0.970 & 0.800 & 0.966 & 0.948 & 0.263 \\
\hline F2 & 0.860 & 0.845 & 0.958 & 0.975 & 0.198 \\
\hline F3 & 0.990 & 0.801 & 0.995 & 0.0 .980 & 0.217 \\
\hline F4 & 0.985 & 0.969 & 0.978 & 0.973 & 0.267 \\
\hline F5 & 0.982 & 0.858 & 0.991 & 0.960 & 0.286 \\
\hline F6 & 0.841 & 0.709 & 0.770 & 0.787 & 0.249 \\
\hline F7 & 0.879 & 0.858 & 0.939 & 0.963 & 0.205 \\
\hline F8 & 0.988 & 0.873 & 0.961 & 0.971 & 0.299 \\
\hline F9 & 0.850 & 0.878 & 0.779 & 0,921 & 0.290 \\
\hline F10 & 0.900 & 0.800 & 0.854 & 0.943 & 0.210 \\
\hline
\end{tabular}

RESULTS AND DISCUSSION: The micropeletes were prepared by the ionotropic gelation of sodium alginate and calcium chloride. Chemical react ion between sodium alginate and calcium chloride to form calcium alginate was utilized for micropeletes of Enalapril core material. From the preliminary studies it is observed that with the increase in stirring speed of the calcium chloride (Counter ion solution), the pellet size is decreased. Also it was found that with the increase in harvesting time, the pellets formed in calcium chloride solution in turn decrease the drug entrapment efficiency. The drug entrapment efficiency of all the formulations were in the range between $70.1 \%$ to $91.8 \%$ as shown in Table-2. Drug entrapment efficiency of micropellets increases with increase in percentage of sodium alginate, hydroxy propyl methyl cellulose, carbopol. But the amount of calcium chloride has no significant effect on the drug entrapment efficiency Enalapril hydrochloride release from the micropeletes was studied in acid buffer ( $\mathrm{pH}$ 1.2) and phosphate buffer ( $\mathrm{pH}$ 7.2) for a period of 8 hrs. The release pattern of micropeletes was slow and spread over extended periods of time. The values of co-efficient of correlation (r) were calculated and were found to be linear for first order release as compared to zero order. Cumulative \% drug released was subjected to curve fitting data using PRISM software. The data was best fitted to Korsmeyer and
Peppa's model and good regression co-efficient was observed (Table 5). The values of diffusion o efficient ranged between $n=0.4286$ to 0.8165 . This indicates that the release of the drug occurs by diffusion following non-fickian transport mechanism. The entrapment efficiency and cumulative percent drug released studies indicated, among the nine formulations F3, F4 and F8a good pattern of release and were represent among of three used polymers selected for the further studies Scanning electron microscopy (SEM) of formulation F3 indicated that the micropeletes gave rough and sandy appearance (fig-2).. The mean particle size for F3, F4 and F8 was found to be $0.611 \mathrm{~mm}, 0.717 \mathrm{~mm}$ and $0.664 \mathrm{~mm}$ respectively. Stability studies conducted at $25 \pm 2 \mathrm{C}$ and $40 \pm 2 \mathrm{C}$ showed that polymers used were compatible with the drug and the formulations were stable.

CONCLUSION: In the present work, microspheres of Enalapril using Sodium alginate along with Carbopol 934, HPMC as copolymers were formulated to deliver Enalapril via oral route. Details regarding the preparation and evaluation of the formulations have been discussed in the previous chapter. From the study following conclusions could be drawn:- The results of this investigation indicate that ionic cross linking technique Ionotropic gelation 
method can be successfully employed to fabricate Enalapril microspheres. The technique provides characteristic advantage over conventional microsphere method, which involves an "allaqueous" system, avoids residual solvents in microspheres. Other methods utilize larger volume of organic solvents, which are costly and hazardous because of the possible explosion, air pollution, toxicity and difficult to remove traces of organic solvent completely. FT-IR spectra of the physical mixture revealed that the drug is compatible with the polymers and copolymers used. Micromeritic studies revealed that the mean particle size of the prepared

\section{REFERENCE:}

1. Thomas Wai-Yip Lee and Joseph R. Robinson, "Controlled / Release Drug-

Delivery Systems",'Remington's

Pharmaceutical Sciences',20 ${ }^{\text {th }}$ Edition,Mack

Publishing Company, Volume-I, 2000; p 903-929.

2. D. M. Brahmankar, Sunil B. Jaiswal., Biopharmaceutics and Pharmacokinetics a Treatise, First edition, Vallabh Prakashan Pitampura, Delhi-2001;p 337-341.

3. Herbert A. Lieberman, Leon Lachman, and Joseph B. Schwartz Pharmaceutical dosage forms IInd Edition Volume-I, p 7-8

4. Edith M. and Mark R.K., "Microencapsulation" in 'Encyclopedia of Controlled Release', John Wiley and Sons, Inc. London, Volume-2, 1998; p 493-510.

5. Chowdary K.P.R. and Sri Ram Murthy A., "Microencapsulation in Pharmacy". Indian Drugs, 1998; 25(10) : p 389-402.

6. Simon Bonita, "A survey of Microencapsulation process"Microencapsulation, Method and Industrial Application' 2nd Edition, Marcel Dekker, Inc. New York, 198; p 2-5.

7. Manekar N.C. and Joshi, S.B., "Microencapsulation Technique". The Eastern Pharmacist, 1998;p 47-49. optimized microspheres was in the size range of $611 \mu \mathrm{m}$ and are suitable for microspheres for oral administration. Increase in the polymer concentration lead to increase in \% Drug entrapment efficiency, Particle size, \% swelling. The invitro drug release decreased with increase in the polymer and copolymer concentration. Analysis of drug release mechanism showed that the drug release from the formulations followed first order kinetics with higuchis model of drug release. Based on the results of evaluation tests formulation coded F3was concluded as best formulation.

8. Patrick B. Deasy, "Microencapsulation and Related Drug Processes", Chapter 1 in 'Drugs and the Pharmaceutical Sciences', 2nd Edition, James Swarbrick, Marcel Dekker Inc, New York, Volume 20, 1984; 113.

9. Vyas and Khar, "Targeted and Controlled Drug Delivery Novel Carrier System” First Edition, C B S Publishers and Distributers, New Delhi, 2002; 419-424.

10. Rajesh, K.S., Khanrah, A. and Biswanath $\mathrm{Sa}$, "Release of Ketoprofen from Alginate Microparticles Containing Film forming Polymer". J. Sci. Ind. Res., 2003, 62(10); 987.

11. Chowdary K. P. R. and N. Koteswara rao, , "Ethyl cellulose microspheres of glipizide: characterization in-vitro and in-vivo evaluation.” Ind. J. Pharm. Sci., 2004; 66 (4), 412-416.

12. Arul B. and R. Kothai, "Formulation and evaluation of chitosan microspheres containing isoniazid", Ind. J. Pharm. Sci., 2003; 66 (5), 640 .

13. Stephen N. Devis and Granner K. Daryl, Alfred Goodman Gilman's The pharmacological basis of therapeutics, 10thEdn., McGraw-Hill, Newyork, 2001; p1686-1705. 
14. Andhimathi M. G., and T. K. Ravi, "Determination of Repaglinide in pharmaceutical formulation by HPLC with UV spectroscopy" Analytical Sci., 2003; (19), p1675-1676.

15. Bhalla H. 1. and Kusha A. V., "Controlled release indomethacin". Indian Drugs, 1988; 26(4) : p 154-157.

16. Chowdary K.P.R. and Suresh Babu K.V.V., "Studies on Micro encapsulation by Calcium
Alginate". The Eastern Pharmacist, 1989; 2 : p 125-126.

17. Pandey S., Singh U.V. Udupa N., "Implantable Flurbiprofen for TreatinInflammation Associated with Arthritis". Indian Drug, 1994; 31(6) : p 254257.

18. Kakkar A. P., "Characterization of Ibuprofen Loaded Microcapsules Prepared by Ionotropic Gelation". Ind. J. Pharm. Sci., 1995; 57(2) : p 56-60. 